\title{
ACTH and Low Melanocortin-2 Receptor Expression Inhibit Infantile Spasm (IS) Seizures in Prenatal Stress (PS) Exposed Rats
}

\author{
Ying Zhang, ${ }^{1}$ Shao-Yong Yuan, ${ }^{2}$ Li-Ping Zou, ${ }^{3,{ }^{*}}$ Ying-Xue Ding, ${ }^{4}$ and Bing $\mathrm{He}^{5}$ \\ ${ }^{1}$ Department of Pediatrics, the Affiliated Hospital of Qingdao University, QingDao, P.R. China \\ ${ }^{2}$ The Chinese people's liberatin army 401 hospital,Qing Dao,P.R. China \\ ${ }^{3}$ Department of Pediatrics, Chinese PLA General Hospital, Beijing, P.R. China \\ ${ }^{4}$ Department of Pediatrics, Beijing Friendship Hospital,Capital Medical University, Beijing, P.R. China \\ ${ }^{5}$ Division of Matrix Biology, Department of Medical Biochemistry and Biophysics, Karolinska Institutet, Stockholm, Sweden \\ "Corresponding author: Dr. Li-Ping Zou, Department of Pediatrics, Chinese PLA General Hospital, 100853, Beijing, China. Tel: +86-1055499016, E-mail: zouliping21@126.com \\ Received 2016 August 03; Revised 2016 November 13; Accepted 2017 April 18.
}

\begin{abstract}
Background: Infantile spasm (IS) is a catastrophic epileptic syndrome of childhood and is usually insensitive to conventional antiepileptic drugs. Studies revealed that prenatal stress (PS) exposure and Melanocortin-2 Receptor (MC2R) may be involved in the pathogenesis of IS. However, the exact mechanism still remains unknown.

Methods: In this study, PS was initially given to Wistar rats and ACTH injection was performed in offsprings. Seizure was then induced and evaluated, followed by MC2R immunohistochemistry and expression detection.

Results: Significant differences in seizure number, MC2R and CRH expressions were observed among different subgroups.

Conclusions: Our study suggested that PS exposure may be an important factor in the pathogenesis of IS. ACTH together with low expression of MC2R, may inhibit IS seizures.
\end{abstract}

Keywords: ACTH, Infantile Spasm, MC2R, Prenatal Stress Exposure

\section{Background}

As a catastrophic epileptic syndrome of childhood, infantile spasm (IS) or West syndrome consists of epileptic spasms, hypsarrhythmia or modified (atypical) hypsarrhythmia (1). Epileptic activity itself may result in behavioral and developmental changes, causing poor cognitive outcome. However, IS is usually insensitive to conventional antiepileptic drugs (AEDs), leading to different treatment from other epileptic status (2).

Numerous studies have suggested that dysregulation of the hypothalamic-pituitary-adrenal (HPA) axis plays an important role in the pathogenesis of IS $(3,4)$. First, adrenocorticotropic hormone (ACTH) can produce the desired effects in the treatment of IS (2); second, levels of ACTH, cortisol, and beta-endorphin in cerebrospinal fluid (CSF) were significantly lower in patients with IS than those in the controls (5); third, corticotrophin releasing hormone $(\mathrm{CRH})$, a rapid and potent convulsant, was reported to cause severe seizures and neuron death in the immature brain areas, which are involved in learning and memory (57).

Recently, more attention in IS have been paid to the influence of prenatal stress exposure on the offspring's endocrine system. In a case-control study, infants whose mothers underwent stress in pregnancy tended to have a higher degree of IS compared with those from the control group (8). Velisek and colleagues found that prenatal betamethasone exposure sensitized rats to the development of NMDA-induced spasms and made it sensitive to ACTH therapy (9), which gave us an evidence for the link between maternal physiology and fetal response. Studies have suggested that excessive prenatal stress exposure may damage the regulatory function of mother's HPA-axis, causing excessive secretion of glucocorticoids. Possibly, these excessive glucocorticoids: 1 ) were then absorbed into fetuses' blood directly by passing through the placental barrier (10); 2) reduce uteroplacental blood flow, causing fetuses' malnutrition and further affecting their HPA-axis accordingly (11); 3) result in increased CRH produced by the placenta, which can enter fetal circulation, and then affect fetal central nervous system developmentat (12).

Melanocortin 2 receptor $(M C 2 R$, also known as ACTH receptor) gene is located in chromosome 18p11.2. Mutations in the coding region of the $M C 2 R$ gene can result in an impaired cAMP response or a loss of sensitivity to ACTH stimulation as well as a loss of high affinity ACTH binding site (13, 14). Our previous work showed that the haplotype of TCCT in MC2R promoter led to significantly increased MC2R expression and was strongly associated with the responsiveness of ACTH therapy in patients with IS $(15,16)$.

Based on these studies, we hypothesize that HPA axis of the offspring is influenced by stress during pregnancy and 
by MC2R mRNA level, which may contribute to the pathogenesis of IS. In the present study, we investigated the correlation between prenatal stress and the pathogenesis of IS in animals and tried to explain the underlying mechanisms.

\section{Methods}

\subsection{Animals}

In total, 15 female Wistar rats at the age of 6-8 weeks were mated with stud males. The presence of vaginal plug indicated gestational day 1 (GD1), and pregnant dams were randomly assigned into two groups (10 in prenatal stress - PS - exposure group, 5 in control group). Offsprings were incorporated into the experiments at postnatal day 13(P13), when brain development corresponded to that of human infants.

\subsection{Prenatal stress Exposure}

PS exposure was administered by placing 10 pregnant rats in a cylindrical glass tank $(46 \mathrm{~cm}$ height $\times 20 \mathrm{~cm}$ diameter) filled with $30 \mathrm{~cm}$ deep water $\left(4 \pm 1^{\circ} \mathrm{C}\right)$ for 5 minutes. Immediately after allowing them to swim, all the rats were removed from the tank, towel dried, and then placed in a warming cage $\left(27^{\circ} \mathrm{C}\right)$. The stress was administered daily at 17:00 from GD1 until parturition.

Five control pregnant females were left undisturbed in their home cages. Day of birth was considered as P0. On P1, offsprings were counted and sex-identified.

\subsection{Seizure Induction and Evaluation}

In total, 30 pups from PS exposure group were randomly sorted into three subgroups: (1)ACTH-treated group (PS-ACTH + NMDA, $\mathrm{n}=10$ ): Intraperitoneal injections of ACTH (ACTH1-24; Sigma) dissolved in saline were given to pups in the dose of $0.4 \mathrm{mg} / \mathrm{kg}$ at 8 A.M. on P13, followed by NMDA injection in the dose of $7 \mathrm{mg} / \mathrm{kg} 30$ minutes later. (2) Placebo-treated group (PS-Saline + NMDA, $n=10$ ): pups received intraperitoneal injections of saline and NMDA with the same protocol used in ACTH-treated group. (3) Normal group (PS- Normal, $\mathrm{n}=10$ ): pups did not receive any injections on P13.

In the control group, 30 pups were also sorted into three subgroups: (1) ACTH treated group (C-ACTH + NMDA, $\mathrm{n}=10$ ); (2) Placebo-treated group (C-Saline + NMDA, $\mathrm{n}=10$ ); (3) Normal group (C-Normal, $n=10$ ). All the treatment was the same as those mentioned in the PS group.

After intraperitoneal injection, the rats were continuously observed for the occurrence of NMDA-specific symptoms. Latency to first onset was recorded and evaluated in detail.

\subsection{MC2R Immunohistochemistry}

A total of 60 adrenal glands were obtained $3 \mathrm{~h}$ after intraperitoneal subcutaneous injections of NMDA or NS. Tissue sections were fixed, decalcified, dehydrated, embedded into paraffin wax, and sectioned at $5 \mu \mathrm{m}$ thickness. A rabbit anti-MC2R (1: 500, Santa Cruz Biotechnology, Cat. No. sc-13107, Santa Cruz, CA, USA) were used for immunolabelling. To detect the antibody, Alexa Fluor 405-conjugated antirabbit IgG (Molecular Probes) were used. The fluorescence microscope BZ-9000 (Keyence) was used for immunofluorescence visualization

\subsection{Quantitative Real-Time PCR (Q-PCR)}

Total RNA was extracted from 60 adrenal glands, followed by purity and integrity assessment by measuring optical density and by electrophoresis on a denaturing agarose gel, respectively. Expressions of $M C 2 R$ and $\mathrm{CRH}$ mRNA were measured by relative quantitative analysis using the ABI PRISM 7500 real-time PCR (RT-PCR) system (Applied Biosystems). All RT-PCR reactions were performed in triplicate. The primers used for RT-PCR amplification of MC2R and CRH cDNA samples are presented in Table 1. Glyceraldehyde-3-phosphate dehydrogenase (GAPDH) was used as an internal control.

Table 1. The Primers Used for MC2R and CRH Amplification

\begin{tabular}{lc}
\hline Primers & Sequence $\left(\mathbf{5}^{\prime}\right.$ - $\mathbf{3}$ ') \\
\hline MC2R-F & TGACCGCTACATCACCATCT \\
\hline MC2R-R & GTGAGCACTGTGGGGATATG \\
\hline CRH-F & TGGATCTCACCTTCCACCTTCTG \\
\hline CRH-R & CCGATAATCTCCATCAGTTTCCTG \\
\hline
\end{tabular}

Data were expressed as the relative quantitation of mRNA expression normalized with GAPDH using the $2^{-\Delta \Delta C T}$ method.

\subsection{Statistical Analysis}

Parametric data were evaluated using ANOVA (three or more groups) with post hoc Fisher's correction for multiple comparisons, as adjusted by the Holm-Sidak method.

\section{Results}

\subsection{Clinical Observations}

Intraperitoneal injection of NMDA into 13-day-old rat pups elicited epilepsy-like symptoms. Rats were observed of seizure activities and latencies during various stages. Specific characteristics of the curling status epilepticus contained spine curling, meeting of head and tail, paws 
curling against the body, formation of a ball-like shape by the entire body, and the presence of singular or continuous spasms. Two pups in PS-saline group underwent tonic seizures or even death. No significant difference in the number of seizures in each group was found between males and females. Significant differences were observed between PS-ACTH and PS-saline groups, C-ACTH and C-saline groups, PS-ACTH and C-ACTH groups as well as PSSaline andC-saline groups, respectively (Table 2, Figure 1).

Table 2. Clinical Characteristics of rats in Different Groups

\begin{tabular}{lccc}
\hline Groups & $\begin{array}{c}\text { Number of Seizures } \\
(\text { Mean } \pm \text { SD })\end{array}$ & $\begin{array}{c}\text { Latency to First Onset } \\
(\text { Mean } \pm \text { SD }) \text {, min }\end{array}$ & Death \\
\hline PS-ACTH & 16 & 33 & 0 \\
PS-Saline & 25 & 15 & 2 \\
\hline C-ACTH & 21 & 22 & 0 \\
\hline C-Saline & 30 & 24 & 0 \\
\hline
\end{tabular}

\subsection{MC2R Immunohistochemistry}

MC2R immunoreactive cells were mainly found in the zona fasiculata and zona glomerulosa of the adrenal glands. Positive cells were elliptically or irregularly shaped with dark brown cytoplasm (Figure 2).

\section{3. $M C 2 R$ and $C R H$ Expressions}

Rat pups with PS exposure showed significantly lower MC2R mRNA expression level than that in the control group $(\mathrm{P}<0.001)$. No significant difference in MC2R expression was found among three PS subgroups and among three control subgroups. In each group no significant difference was observed between male and female (Table 3 ).

Table 3. Expression Levels of MC2R and $\mathrm{CRH}^{\mathrm{a}}$

\begin{tabular}{lcc}
\hline Groups & MC2R & CRH \\
\hline PS-ACTH & $0.389 \pm 0.060$ & $0.7784 \pm 0.2693$ \\
PS-Saline & $0.397 \pm 0.074$ & $0.6348 \pm 0.3389$ \\
PS- Normal & $0.403 \pm 0.078$ & $0.5842 \pm 0.4207$ \\
C-ACTH & $3.263 \pm 1.234$ & $0.4201 \pm 0.2340$ \\
\hline C-Saline & $3.219 \pm 1.321$ & $0.3210 \pm 0.1138$ \\
C-Normal & $3.159 \pm 0.548$ & $0.2138 \pm 0.2751$ \\
\hline
\end{tabular}

${ }^{\mathrm{a}}$ Values are expressed as mean $\pm \mathrm{SD}$.

Significant higher CRH expression was found in rat pups with PS treatment when compared with that in the control group $(\mathrm{P}<0.005)$. Three subgroups with PS treatment showed no significant difference in CRH expression and the same expression pattern was also found among three subgroups in the control. No significant difference between male and female was observed in each group (Table 3).

\section{Discussion}

IS, also known as West syndrome, is an age-dependent epileptic disease that occurs during infancy. Recently proposed hypotheses, including $\mathrm{CRH}$ and the dysfunction of the HPA axis, provide reasonable explanations for the pathogenesis of IS. ACTH is considered as the most effective drug for infant convulsions. However, there are no reasonable explanations yet for the mechanisms underlying the success in treating infant spasms and the tolerance to ACTH $(17,18)$. Thus, the pathological mechanism of infant convulsions and the mechanism of ACTH in treating infant convulsions must be determined to prevent seizures and improve psychomotor retardation. An understanding of these mechanisms may lead to treatment for infant convulsions.

$\mathrm{MC2}$ is the only melanocorin receptor with a high affinity for ACTH. After secretion in the pituitary, ACTH arrives at the adrenal cortex in the circulatory system to bind to MC2R, thus inducing the secretion of steroid hormones (19). In the adrenal cortex, MC2R is mainly expressed in the zona fasciculata and zona glomerulosa, and acts as a mediator to regulate the secretion of glucocorticoids and mineralcorticoids, respectively (20). Human MC2R expression is positively regulated by ligand ACTH through the CAMP signaling pathway. Missense mutation of the MC2R gene (S74I, I44M and R146H) can result in familial glucocorticoid deficiency Type 1(FGD Type 1), impairment of the maximal response rate of MC2R to cAMP or loss of sensitivity for cAMP production, which can damage receptor function (21).

The present study showed that the offspring from stressed pregnant mice expressed significantly more NMDA-induced seizure attacks than those in the control group. These attacks were reduced by treatment with ACTH, implying that ACTH plays a protective role in seizure attacks. For the HPA axis, all types of stimuli and adverse events can stimulate the synthesis and release of $\mathrm{CRH}$, which, in turn, promotes the release of ACTH. Meanwhile, ACTH binding to the MC2R helps to promote the secretion of adrenal glucocorticoids. This subsequently increases the level of cortisol and eventually inhibits the synthesis and secretion of CRH through a negative feedback mechanism (22). MC2R specifically binds to ACTH, but shows no obvious affinity to other melanocortins. ACTH/MC2R is an important endocrine signaling molecule modulating the HPA axis. ACTH down-regulates the excessive secretion 

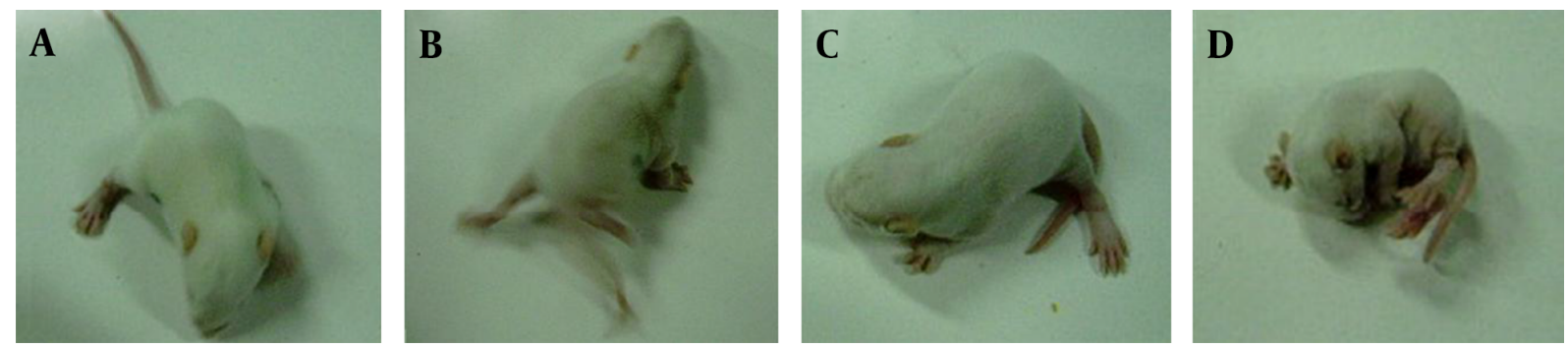

Figure 1. Seizures Onset of Rats After Receiving NMDA Injection. A-1, Excited and more Activities; A-2, Pendular Movement; A-3, Nodding and Spine Curling; A-4, Formation of a Ball-Like Shape by the Entire Body
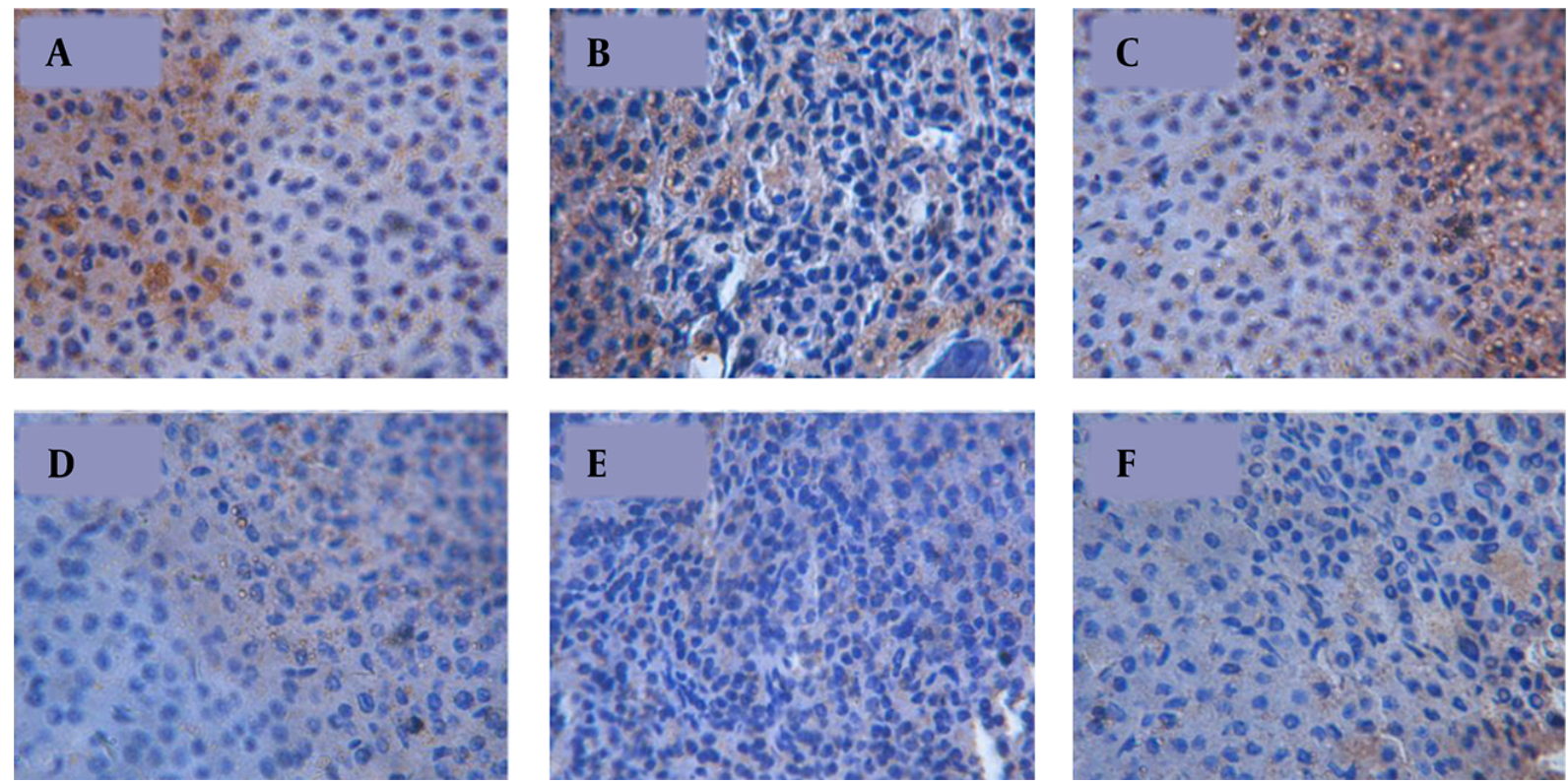

Figure 2. MC2R Immunohistochemistry Analysis. Rat Pups with PS Exposure (B-1, B-2, B-3) Showed Significantly Lower MC2R mRNA Expression Level than that in the Control Group $(\mathrm{C}-1, \mathrm{C}-2, \mathrm{C}-3)(\mathrm{P}<0.001)$

and release of $\mathrm{CRH}$ in some brain areas, reduces neuronal excitability in infant spasms, and has an anticonvulsant effect through the following pathways: 1) binding to MC2R to promote the secretion of adrenal glucocorticoids and maintain plasma cortisol levels at a stabilized higher level; and 2) directly stimulating the melanocortin 4 receptor (MC4R) in the central amygdala resulting in a cortisol independent effect (23). Through long and short feedback mechanisms, these two pathways can inhibit the synthesis and secretion of the convulsive agent CRH, effectively controlling convulsive seizures and relieving the hypsarrhythmic EEG pattern. Moreover, ACTH can enhance the transcription rate of $\mathrm{MC} 2 \mathrm{R}$ and prolong the half-life of MC2R mRNA (15). In addition, our study showed that $\mathrm{MC} 2 \mathrm{R}$ mRNA levels in stressed pregnant mice were also significantly lower than those in the control group. Lower levels of MC2R resulted in the incomplete binding of ACTH to MC2R which, in turn, led to more seizures and a shorter latency in the stressed group than in the control group.

\subsection{Conclusion}

Our results showed that PS exposure may be an important factor in the pathogenesis of IS, and ACTH together with low expression of melanocortin-2 receptor, may inhibit IS seizures.

\section{References}

1. Riikonen R. Recent advances in the pharmacotherapy of infantile spasms. CNS Drugs. 2014;28(4):279-90. doi:10.1007/s40263-014-0139-5. [PubMed: 24504827]. 
2. Mackay MT, Weiss SK, Adams-Webber T, Ashwal S, Stephens D, Ballaban-Gill K, et al. Practice parameter: medical treatment of infantile spasms: report of the American Academy of Neurology and the Child Neurology Society. Neurology. 2004;62(10):1668-81. doi: 10.1212/01.WNL.0000127773.72699.C8. [PubMed:15159460].

3. Frost JJ, Hrachovy RA. Pathogenesis of infantile spasms: a model based on developmental desynchronization. J Clin Neurophysiol. 2005;22(1):25-36. doi: 10.1097/01.WNP.0000149893.12678.44. [PubMed: 15689710].

4. Nagamitsu S, Matsuishi T, Yamashita Y, Shimizu T, Iwanaga R, Murakami Y, et al. Decreased cerebrospinal fluid levels of betaendorphin and ACTH in children with infantile spasms. $J$ Neural Transm (Vienna). 2001;108(3):363-71. doi: 10.1007/s007020170081. [PubMed: 11341487].

5. Brunson KL, Avishai-Eliner S, Baram TZ. ACTH treatment of infantile spasms: mechanisms of its effects in modulation of neuronal excitability. Int Rev Neurobiol. 2002;49:185-97. doi: 10.1016/S00747742(02)49013-7. [PubMed: 12040892].

6. Brunson KL, Khan N, Eghbal-Ahmadi M, Baram TZ. Corticotropin (ACTH) acts directly on amygdala neurons to down-regulate corticotropin-releasing hormone gene expression. Ann Neurol. 2001;49(3):304-12. doi:10.1002/ana.66.abs. [PubMed: 11261504].

7. Brunson KL, Eghbal-Ahmadi M, Baram TZ. How do the many etiologies of West syndrome lead to excitability and seizures? The corticotropin releasing hormone excess hypothesis. Brain Dev. 2001;23(7):533-8. doi: 10.1016/S0387-7604(01)00312-6. [PubMed: 11701250].

8. Shang NX, Zou LP, Zhao JB, Zhang F, Li H. Association between prenatal stress and infantile spasms: a case-control study in China. Pediatr Neurol. 2010;42(3):181-6. doi: 10.1016/j.pediatrneurol.2009.09.003. [PubMed: 20159427].

9. Velisek L, Jehle K, Asche S, Veliskova J. Model of infantile spasms induced by N-methyl-D-aspartic acid in prenatally impaired brain. Ann Neurol. 2007;61(2):109-19. doi:10.1002/ana.21082. [PubMed: 17315208].

10. Gitau R, Cameron A, Fisk NM, Glover V. Fetal exposure to maternal cortisol. Lancet. 1998;352(9129):707-8. doi: 10.1016/S0140-6736(05)608240. [PubMed: 9728994].

11. de Weerth C, Buitelaar JK. Physiological stress reactivity in human pregnancy-a review. Neurosci Biobehav Rev. 2005;29(2):295-312. doi: 10.1016/j.neubiorev.2004.10.005. [PubMed: 15811500].

12. Majzoub JA, Karalis KP. Placental corticotropin-releasing hormone: function and regulation. Am J Obstet Gynecol. 1999;180(1 Pt 3):S242-6. doi:10.1016/S0002-9378(99)70708-8. [PubMed: 9914625].

13. Metherell LA, Chan LF, Clark AJ. The genetics of ACTH resistance syn- dromes. Best Pract Res Clin Endocrinol Metab. 2006;20(4):547-60. doi: 10.1016/j.beem.2006.09.002. [PubMed: 17161331].

14. Penhoat A, Naville D, El Mourabit H, Buronfosse A, Berberoglu M, Ocal $\mathrm{G}$, et al. Functional relationships between three novel homozygous mutations in the ACTH receptor gene and familial glucocorticoid deficiency. J Mol Med (Berl). 2002;80(7):406-11. doi: 10.1007/s00109-0020333-7. [PubMed: 12110946].

15. Liu ZL, He B, Fang F, Tang CY, Zou LP. Genetic polymorphisms of MC2R gene associated with responsiveness to adrenocorticotropic hormone therapy in infantile spasms. Chin Med J (Engl). 2008;121(17):162732. [PubMed: 19024088].

16. Ding YX, Zou LP, He B, Yue WH, Liu ZL, Zhang D. ACTH receptor (MC2R) promoter variants associated with infantile spasms modulate MC2R expression and responsiveness to ACTH. Pharmacogenet Genomics. 2010;20(2):71-6. doi: 10.1097/FPC.0b013e328333a172. [PubMed: 20042918].

17. Lux AL, Edwards SW, Hancock E, Johnson AL, Kennedy CR, Newton RW, et al. The United Kingdom Infantile Spasms Study comparing vigabatrin with prednisolone or tetracosactide at 14 days: a multicentre, randomised controlled trial. Lancet. 2004;364(9447):1773-8. doi: 10.1016/S0140-6736(04)17400-X. [PubMed: 15541450].

18. Riikonen R. Infantile spasms: therapy and outcome. J Child Neurol. 2004;19(6):401-4. doi: 10.1177/088307380401900601. [PubMed: 15446386].

19. Schioth HB, Chhajlani V, Muceniece R, Klusa V, Wikberg JE. Major pharmacological distinction of the ACTH receptor from other melanocortin receptors. Life Sci. 1996;59(10):797-801. doi: 10.1016/0024-3205(96)00370-0. [PubMed: 8761313].

20. Xia Y, Wikberg JE. Localization of ACTH receptor mRNA by in situ hybridization in mouse adrenal gland. Cell Tissue Res. 1996;286(1):63-8. doi: 10.1007/s004410050675. [PubMed: 8781213].

21. Elias LL, Huebner A, Pullinger GD, Mirtella A, Clark AJ. Functional characterization of naturally occurring mutations of the human adrenocorticotropin receptor: poor correlation of phenotype and genotype. J Clin Endocrinol Metab. 1999;84(8):2766-70. doi: 10.1210/jcem.84.8.5924. [PubMed:10443676].

22. Catania A, Gatti S, Colombo G, Lipton JM. Targeting melanocortin receptors as a novel strategy to control inflammation. Pharmacol Rev. 2004;56(1):1-29. doi: 10.1124/pr.56.1.1. [PubMed: 15001661].

23. Beuschlein F, Fassnacht M, Klink A, Allolio B, Reincke M. ACTHreceptor expression, regulation and role in adrenocortial tumor formation. Eur J Endocrinol. 2001;144(3):199-206. [PubMed:11248736]. 